\title{
AUTISMO NA ADOLESCÊNCIA UMA REVISÃO INTEGRATIVA DA LITERATURA
}

FABIANA SERBAI ${ }^{1}$

ORCID: https://orcid.org/ 0000-0002-9309-4215

ELIS MARIA TEIXEIRA PALMA PRIOTTO²

ORCID: https://orcid.org/0000-0003-1949-2183

\begin{abstract}
RESUMO: O transtorno do espectro autista (TEA) é considerado um distúrbio do neurodesenvolvimento, caracterizado pela dificuldade de relacionamento interpessoal. Cerca de 1\% da população é diagnosticada com esse transtorno em algum nível. A presente revisão investiga como se caracterizam, entre os anos de 2015 e 2020, as publicações científicas nacionais e internacionais de língua espanhola e portuguesa sobre o transtorno do espectro autista na adolescência. Adota metodologia qualitativa com revisão integrativa de literatura nas bases de dados virtuais BVS, Scielo, Lilacs, Medline e PubMed, utilizando os descritores "transtorno do espectro autista", "autismo", "transtorno autístico", "adolescência" e "adolescente". Delimita os artigos com ênfase no comportamento e inteligência de adolescentes autistas. Tem como resultado nove artigos identificados, sistematizados e analisados. Conclui que existem diferentes olhares sobre o autismo na adolescência e como ponto comum a preocupação com os aspectos relacionados ao comportamento, as habilidades de comunicação e a autonomia.
\end{abstract}

Palavras-chave: Transtorno do espectro autista, adolescência, comportamento, inteligência

\section{AUTISM IN ADOLESCENCE AN INTEGRATIVE LITERATURE REVIEW}

\begin{abstract}
Autism Spectrum Disorder (ASD) is considered a neurodevelopmental disorder, characterized by the difficulty of interpersonal relationships. About $1 \%$ of the population is diagnosed with this disorder at some level. This review investigates how national and international scientific publications on autism spectrum disorder in adolescence are characterized between 2015 and 2020. It adopts a qualitative methodology with an integrative literature review in the virtual databases BVS, Scielo, Lilacs, Medline and Pubmed, using the descriptors "autistic spectrum disorder", "autism", "autistic disorder", "adolescence" and "adolescent". It delimits the articles with emphasis on the behavior and intelligence of autistic adolescents. It results in nine articles identified, systematized and analyzed. It concludes that there are different perspectives on autism in adolescence and as a common point concern with aspects related to behavior, communication skills and autonomy.
\end{abstract}

Keywords: Autistic spectrum disorder, adolescence, behavior, intelligence

\footnotetext{
${ }^{1}$ Universidade Estadual do Oeste do Paraná (UNIOESTE). Foz do Iguaçu, PR, Brasil. < fabiserbai@gmail.com>

${ }^{2}$ Universidade Estadual do Oeste do Paraná (UNIOESTE). Foz do Iguaçu, PR, Brasil. <elispriotto@gmail.com> Educação em Revista|Belo Horizonte|v.37|e26472|2021
} 


\section{EL AUTISMO EN LA ADOLESCENCIA UNA REVISIÓN INTEGRATIVA DE LA LITERATURA}

\section{RESÚMEN:}

El trastorno del espectro autista (TEA) se considera un trastorno del neurodesarrollo, caracterizado por dificultad en las relaciones interpersonales. Alrededor del 1\% de la población es diagnosticada con este trastorno en algún nível. Esta revisión investiga cómo se caracterizan, entre 2015 y 2020, las publicaciones científicas nacionales e internacionales en lengua española y portuguesa sobre el trastorno del espectro autista en la adolescencia. Adopta metodología cualitativa con revisión integradora de la literatura en las bases de datos virtuales BVS, Scielo, Lilacs; Medline y PubMed, utilizando los descriptores "trastorno del espectro autista", "autismo", "trastorno autista", "adolescencia" y "adolescente". Delimita artículos con énfasis en el comportamiento e inteligencia de los adolescentes autistas. Da como resultado nueve artículos identificados, sistematizados y analizados. Se concluye que existen diferentes visiones sobre el autismo en la adolescencia y, como punto común, la preocupación por aspectos relacionados con la conducta, las habilidades comunicativas y la autonomía.

Palabras clave: Trastorno del espectro autista, adolescencia, comportamiento, inteligencia 


\section{INTRODUÇÃO}

O autismo é considerado um distúrbio do neurodesenvolvimento, caracterizado pela dificuldade de relacionamento interpessoal, isolamento social e bloqueio de relacionamento com o meio social (PAULON, 2005; TCHUMAN; RAPIN, 2009; TEODORO; 2016). O Manual de Diagnósticos e Estatísticas dos Transtornos Mentais - DSM-5 (2013), apresenta o Transtorno do Espectro Autista (TEA) composto pelos transtornos autista, transtorno de Asperger e transtorno global do desenvolvimento por apresentarem características semelhantes relacionadas a prejuízos na comunicação e interação social e padrões de comportamento restritivos e repetitivos.

Indivíduos que apresentam o TEA, segundo o DSM-5 (2013), exibem as características do transtorno muito cedo, porém algumas características podem ser mascaradas pela falta de exigência social do ambiente em que vivem, o que dificulta o diagnóstico. Por ser um transtorno heterogêneo, com diversas nuances, o DSM-5 (2013), classifica o autismo pelo grau de exigência de cada nível, possuindo assim três tipos de classificação: o nível 1 - Exigindo apoio, o nível 2 - Exigindo apoio substancial e o nível 3 - Exigindo apoio muito substancial.

A explicação científica para o desenvolvimento do TEA ainda está sendo elucidada, porém já foi relacionado à maternagem insuficiente (conceito de mãe-geladeira), no qual se atribuía o TEA à relação afetiva ineficiente entre mãe e bebê (KLIN, MERCADANTE, 2006; SEVILLA, BERMÚDEZ, SÁNCHES, 2013). Atualmente, este tipo de explicação é pouco aceita e outras são exploradas para tentar esclarecer as causas deste distúrbio, sendo os aspectos genéticos e ambientais os que se sobressaem nas pesquisas recentes.

O diagnóstico de TEA geralmente ocorre durante a infância, Bagarollo e Panhoca (2011) afirmam que o sofrimento das famílias quanto à descoberta da criança com TEA se inicia nos primeiros sintomas e se agrava com a confirmação do diagnóstico. A família passa por um longo período de estresse e dificuldades quanto ao modo de agir com a criança, e a rotina familiar e social desses indivíduos tornase prejudicada, o que pode se estender por toda a vida. Sobre isto, Minatel e Matsukura (2015, p. 430) destacam:

Sendo uma condição crônica, os desafios e demandas vivenciadas por esses indivíduos e familiares se modificam ao longo do tempo, podendo ter maior ou menor impacto a depender das possibilidades de desenvolvimento da pessoa com autismo e do seu grupo familiar, dos contextos que estão inseridos e dos recursos e apoio disponíveis às famílias.

$\mathrm{Na}$ adolescência, de acordo com Klin (2006), os autistas podem sofrer um declínio comportamental, apresentando rebaixamento de habilidades de linguagem e sociabilidade. Afirma que estes adolescentes podem apresentar sintomas de ansiedade e depressão relacionadas ao grau de consciência sobre si mesmo e de sua incapacidade de estabelecer amizades, iniciar conversar e interagir com os pares. Muitas vezes, estas crianças e adolescentes são vítimas de abusos psicológicos e físicos pela falta de habilidade em interagir. O acúmulo destas frustrações pode torná-los ainda mais introspectivos.

Para Hervas (2012), os sintomas do autismo apresentam considerável melhora com o passar da idade e na adolescência é perceptível as dificuldades relacionadas às necessidades sociais como comunicação. A autora pontua que, para o adolescente autista, as dificuldades de relacionamento entre os pares e com pessoas de seu interesse são mais complexas ou praticamente impossíveis. As dificuldades de autonomia, desenvolvimento psicoafetivo são somadas às demandas cada vez maiores do processo educacional e social.

Hervas (2012) esclarece que são necessários recursos individualizados para o desenvolvimento destes sujeitos e Klin (2006) evidencia que a maioria das crianças autistas, quando adequadamente estimuladas, a longo prazo, conseguem atingir algum grau de autossuficiência quando adultos. Dados estatísticos demonstram que o TEA se manifesta predominantemente em pessoas do sexo masculino, sendo a relação de 3,5 a 4,0 meninos para cada menina (MAENNER, SHAW, BAIO, et al., 2020). Entretanto, ressalta-se que o sexo feminino é subdiagnosticado para o TEA. Hull, Petrides e Mandy (2020) explicam que isto se deve a diferenças qualitativas na maneira que as meninas expressam as características do transtorno, tais como, comportamentos adicionais ou não incluídos nos critérios tradicionais de diagnóstico. 
Pesquisas afirmam que $1 \%$ da população é diagnosticada como autista em algum nível (CAMARGO, BOSA, 2009; GOMES et al., 2015). Pesquisas estadunidenses demonstram que a incidência de autismo em crianças em idade escolar é de 1 para cada 54 crianças (MAENNER, SHAW, BAIO, et al., 2020). Camargo et al. (2020) mostram que no Brasil não há dados sobre o assunto, porém estima-se que dois milhões de brasileiros possuem TEA em algum nível e esta estimativa tende a aumentar. Neste sentido julgamos importante o levantamento de pesquisas sobre o autismo na adolescência, sendo esta uma fase intermédia entre a vida infantil e a vida adulta, marcada socialmente por dificuldades intrínsecas ao período e que podem se agravar com a presença de um transtorno como o TEA.

O objetivo deste artigo é construir uma revisão integrativa sobre o TEA na adolescência caracterizando ao longo dos últimos cinco anos as publicações científicas nacionais e internacionais de língua espanhola e portuguesa sobre adolescentes com o Transtorno do Espectro Autista com ênfase na inteligência e comportamento.

\section{MÉTODO}

Este artigo refere-se a uma revisão integrativa da literatura em bases científicas da área da saúde e educação por meio de levantamento da publicação científica qualitativa sobre o Transtorno do Espectro Autista e Adolescência.

A revisão integrativa de literatura permite maior abrangência de explicações de um mesmo assunto. Por meio deste método, é possível realizar a análise de dados de pesquisas sobre determinado tema de forma sistemática e ordenada, contribuindo para o desenvolvimento de conhecimento na área estudada (ROMAN, FRIEDLANDER, 1998; ERCOLE, MELO, ALCOFORADO, 2014). "Combina dados da literatura teórica e empírica, além de incorporar um vasto leque de propósitos" (SOUZA, SILVA, CARVALHO, 2010, p. 103). E a análise qualitativa procura compreender e interpretar da forma mais fiel possível a lógica interna dos sujeitos que estuda e dá conhecimento de sua verdade (MINAYO, 2012).

Para conduzir esta revisão de pesquisas, delineou-se os seguintes processos: identificação do tema de pesquisa; busca na literatura sobre os estudos; avaliação, análise e síntese dos dados; apresentação e conclusões. Como ponto de partida, o estudo teve como pergunta norteadora a responder: como se caracterizam, ao longo dos últimos cinco anos, as publicações científicas nacionais e internacionais no idioma espanhol e português sobre adolescentes com o Transtorno do Espectro Autista?

Com o propósito de responder a esse questionamento, fizemos o processo de pesquisa, coleta, seleção e sistematização dos artigos adotando a sequência a seguir: os artigos foram pesquisados nas bases de dados virtuais Portal Biblioteca Virtual em Saúde (BVS), Scielo (Scientific Electronic Library Online); Lilacs (Literatura Latino-Americana e do Caribe em Ciências da Saúde); Medline (Literatura Internacional em Ciências da Saúde); e, PubMed (National Library of Medicine).

Sendo utilizada a combinação dos descritores padronizados e disponíveis nos Descritores em Ciências da Saúde (DeCS): Adolescente, Puberdade, Transtorno do Espectro Autista e Transtorno Autístico, empregados separadamente ou combinados - o uso do operador booleano AND - para obter o maior número de produções científicas. Os filtros foram estabelecidos de acordo com os critérios de inclusão e exclusão.

A partir do cruzamento dos descritores, os artigos encontrados foram selecionados por meio dos critérios de inclusão: artigos completos em periódicos, publicados entre 2015 a 2020 (cinco anos), redigidos no idioma português ou espanhol, e; aqueles que apresentam como objeto central do estudo adolescentes autistas e inteligência ou comportamento. Foram excluídos os artigos incompletos, as revisões sistemáticas e as meta-análises, os publicados antes de 2015, repetidos ou duplicados e aqueles que não são pertinentes ao tema da pesquisa. A figura 01 apresenta o fluxograma da dinâmica de seleção dos artigos. 
Figura 01- Artigos selecionados, período de 2015 a 2020

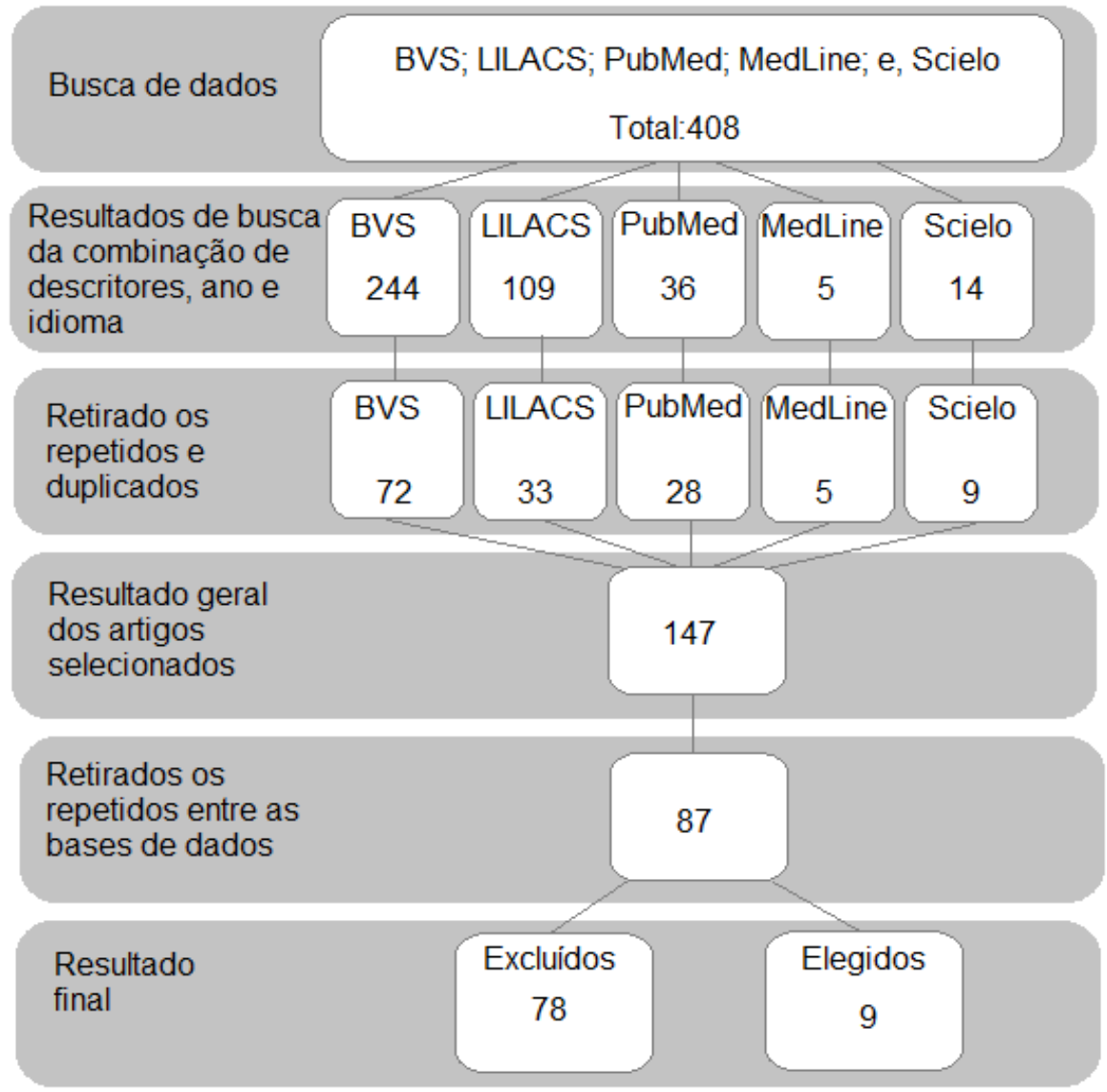

Fonte: As autoras, 2020

Após a leitura dos títulos e resumos, os artigos foram selecionados respeitando-se os critérios de inclusão e exclusão, foi realizada a leitura na íntegra das publicações e na sequência foram sistematizadas em duas tabelas distintas, a quadro 01, apresentando os autores, ano de publicação, título, Digital Object Identifier (DOI), e a quadro 02, mostrando as palavras-chave, objetivos e resultados.

Quadro 01- Identificação dos artigos selecionados, período de 2015 a 2020

\begin{tabular}{|c|c|c|c|c|}
\hline TÍTULO & AUTORES & ANO & IDIOMA & DOI \\
\hline $\begin{array}{c}\text { (1) Dançaterapia no autismo: } \\
\text { um estudo de caso }\end{array}$ & $\begin{array}{c}\text { MACHADO, Lavinia } \\
\text { Teixeira }\end{array}$ & 2015 & Português & $\begin{array}{l}10.590 / 1809- \\
2950 / 1113732202 \\
2015\end{array}$ \\
\hline $\begin{array}{l}\text { (2) Procesamiento semántico } \\
\text { de palabras epistémicas y } \\
\text { metafísicas en niños y } \\
\text { adolescentes con Trastorno de } \\
\text { Espectro Autista (TEA) y con } \\
\text { Desarrollo Típico (DT). }\end{array}$ & $\begin{array}{l}\text { JUILLERAT, Karen; } \\
\text { CORNEJO, Felipe; } \\
\text { CASTILLO } \\
\text { GUEVARA, Ramon; } \\
\text { CHAIGNEAU, } \\
\text { Sergio }\end{array}$ & 2015 & Espanhol & $\begin{array}{c}10.4067 / \mathrm{S} 0718- \\
480820150003000 \\
06 .\end{array}$ \\
\hline $\begin{array}{l}\text { (3) Frequência de sobrepeso e } \\
\text { obesidade em crianças e } \\
\text { adolescentes com autismo e } \\
\text { transtorno do déficit de } \\
\text { atenção/hiperatividade }\end{array}$ & $\begin{array}{c}\text { KUMMER, Arthur; } \\
\text { BARBOSA, Izabela } \\
\text { Guimarães; } \\
\text { RODRIGUES, } \\
\text { David Henrique; }\end{array}$ & 2016 & Português & $\begin{array}{c}\text { 10.1016/j.rppede. } 2 \\
015.12 .006\end{array}$ \\
\hline
\end{tabular}




\begin{tabular}{|c|c|c|c|c|}
\hline & $\begin{array}{c}\text { ROCHA, Natália } \\
\text { Pessoa; RAFAEL, } \\
\text { Marianna da Silva; } \\
\text { PFEILSTICKER, } \\
\text { Larissa; SILVA, Ana } \\
\text { Cristina Simões; } \\
\text { TEIXEIRA, Antônio } \\
\text { Lúcio }\end{array}$ & & & \\
\hline $\begin{array}{l}\text { (4) Evolución y seguimiento de } \\
\text { adolescentes y adultos jóvenes } \\
\text { con autismo }\end{array}$ & $\begin{array}{c}\text { FLAGGE, Noris } \\
\text { Moreno de }\end{array}$ & 2017 & Espanhol & \\
\hline $\begin{array}{l}\text { (5) Desempenho no teste de } \\
\text { raven: diferenças entre } \\
\text { crianças-adolescentes com } \\
\text { transtorno do espectro autista } \\
\text { e com dificuldades de leitura }\end{array}$ & $\begin{array}{l}\text { SBICIGO, Juliana } \\
\text { Burges; BOSA, } \\
\text { Cleonice } \\
\text { Alves; BANDEIRA, } \\
\text { Denise } \\
\text { Ruschel; TEIXEIRA, } \\
\text { Maria Cristina } \\
\text { Triguero } \\
\text { Veloz; SALLES, } \\
\text { Jerusa Fumagalli de }\end{array}$ & 2019 & Português & $\begin{array}{l}\text { 10.15689/ap.2019. } \\
1802.16917 .10\end{array}$ \\
\hline $\begin{array}{l}\text { (6) Funciones ejecutivas y } \\
\text { bienestar subjetivo en alumnos } \\
\text { que presentan trastorno del } \\
\text { espectro autista e inteligencia } \\
\text { sobre el rango promedio }\end{array}$ & $\begin{array}{l}\text { AGURTO,Catalina } \\
\text { Sabat; PERES- } \\
\text { SALAS,Claudia; } \\
\text { OYANADEL- } \\
\text { VÉLIZ, Cristian } \\
\end{array}$ & 2019 & Espanhol & $\begin{array}{c}10.5839 / \text { rcnp. } 201 \\
9.14 .02 .05\end{array}$ \\
\hline $\begin{array}{l}\text { (7) Calidad de vida en niños y } \\
\text { adolescentes con trastorno del } \\
\text { espectro autista sin } \\
\text { discapacidad intelectual }\end{array}$ & $\begin{array}{l}\text { CUESTA-GÓMEZ, } \\
\text { José Luis; } \\
\text { VIDRIALES- } \\
\text { FERNÁNDEZ, } \\
\text { Ruth; CARVAJAL- } \\
\text { MOLINA, Fernando }\end{array}$ & 2016 & Espanhol & $\begin{array}{c}10.33588 / \text { rn.62S0 } \\
1.2015524\end{array}$ \\
\hline $\begin{array}{l}\text { (8) La función ejecutiva está } \\
\text { alterada en los trastornos del } \\
\text { espectro autista, pero esta no } \\
\text { correlaciona con la inteligencia }\end{array}$ & $\begin{array}{l}\text { MERCHÁN- } \\
\text { NARANJO,Jessica; } \\
\text { BOADA, Leticia; } \\
\text { REY-MEJÍAS, Ángel } \\
\text { del, MAYORAL, } \\
\text { María; LLORENTE, } \\
\text { Cloe; ARANGO, } \\
\text { Celso; } \\
\text { PARELLADA, Mara }\end{array}$ & 2016 & Espanhol & $\begin{array}{c}10.1016 / \mathrm{j} . \mathrm{rpsm} .20 \\
15.10 .005\end{array}$ \\
\hline $\begin{array}{l}\text { (9) Identificando compulsiones } \\
\text { en niños y adolescentes con } \\
\text { trastorno del espectro autista }\end{array}$ & $\begin{array}{l}\text { ORTIZ, Ana. E; } \\
\text { ESPELT, Clara; } \\
\text { ROSA, Mireia; } \\
\text { PUIG, Olga } \\
\text { LÁZARO, Luisa; } \\
\text { CALVO, Rosa }\end{array}$ & 2019 & Espanhol & $\begin{array}{c}10.31766 / \text { revpsij.v } \\
\text { 36n4a4 }\end{array}$ \\
\hline
\end{tabular}

Fonte: As autoras, 2020 
Quadro 02 - Palavras-chave, objetivos e resultados dos artigos selecionados, período de 2015 a 2020

\begin{tabular}{c}
\hline PALAVRAS - CHAVE \\
\hline \\
(1) Transtorno Autístico; \\
Terapia através da Dança; \\
Marcha, Terapias \\
Complementares; \\
Destreza Motora
\end{tabular}

(2) Raciocínio,
processamento semântico
e teoria da mente.

(3) Transtorno do déficit de atenção e hiperatividade; Transtorno autístico; Obesidade pediátrica; Sobrepeso
Este artigo proporciona evidência experimental, onde o processamento de palavras abstratasepistêmicas (v.g. imaginação, certeza) é diferente ao processamento de palavras abstratasmetafísicas (v.g. liberdade, critério).

Avaliar a frequência de sobrepeso e obesidade em crianças e adolescentes com transtorno do espectro do autismo (TEA) e transtorno do déficit de

atenção/hiperatividade (TDAH) e em seus pais, em comparação com crianças e adolescentes da comunidade sem transtornos do desenvolvimento.

Avaliar a evolução das características clínicas de

(4) Espectro autista, trajetória de desenvolvimento, grau de independência um grupo de pacientes com

Transtorno do Espectro Autista (TEA), sua adaptação e independência na adolescência e vida adulta e necessidades atuais.
RESULTADOS

Segundo a Medida da Função Motora, o escore total aumentou $27,08 \%$; o Teste de Tinetti referente ao equilíbrio aumentou de 68 para $75 \%$ e a marcha de $16 \%$ para $66 \%$; o CARS (Childhood Autism Rating Scale) foi alterado de 41,5 para 34 pontos, transferindo o transtorno de grave para moderado dentro dos parâmetros propostos. A dançaterapia pode otimizar o comportamento neuropsicomotor de jovens com transtornos autistas.

Os sujeitos com TEA foram menos precisos e lentos com palavras epistêmicas-abstratas, e lentos com palavras abstratas-metafísicas que os sujeitos com DT. Os resultados são discutidos em termos dos processos cognitivos e sociais para detectar e entender os estados mentais, uma habilidade chamada teoria da mente (ToM).

Crianças e adolescentes com TEA e TDAH exibiram maior percentil $(p<0,01)$ e escore- $z(p<0,01)$ do IMC em relação aos controles, bem como frequência mais elevada de sobrepeso e obesidade $(p=0,04)$. Os pacientes com TEA e TDAH não diferiram entre si quanto a essas variáveis ou quanto à circunferência abdominal. Os pais das crianças com TEA e TDAH também não diferiram entre si.

O seguimento médio a partir do diagnóstico foi de 15 anos. A evolução foi heterogênea, melhorando linguagem e comunicação na maioria, mas persistindo problemas na socialização. O fim dos estereótipos ocorreu em 33\% dos casos antes dos 5 anos, persistindo em menor grau em $44 \%$ dos pacientes. $23 \%$ dos casos apresentam comorbidade com epilepsia. $40 \%$ da população revelou deficiência intelectual (DI) leve. No total $13 \%$ participa de algum 


\begin{tabular}{|c|c|c|}
\hline & & $\begin{array}{l}\text { programa especial dirigido ao } \\
\text { treinamento de habilidades para a } \\
\text { autonomia e vida independente ou } \\
\text { educativo vocacional. }\end{array}$ \\
\hline $\begin{array}{l}\text { (5) Inteligência; autismo; } \\
\text { dislexia; distúrbios da } \\
\text { leitura; matrizes } \\
\text { progressivas. }\end{array}$ & $\begin{array}{c}\text { Comparar o desempenho de } \\
\text { crianças e adolescentes com } \\
\text { Transtorno do Espectro } \\
\text { Autista (TEA) e com } \\
\text { Dificuldades de Leitura } \\
\text { (DL) no Teste de Matrizes } \\
\text { Progressivas Coloridas de } \\
\text { Raven (MPCR). }\end{array}$ & $\begin{array}{l}\text { Controlando o efeito da idade, houve } \\
\text { desempenho superior do grupo TEA } \\
\text { na Parte A do MPCR. O grupo DL } \\
\text { apresentou desempenho inferior aos } \\
\text { demais grupos na Parte A e no escore } \\
\text { total do teste se comparado ao grupo } \\
\text { DT. O desempenho do grupo TEA foi } \\
\text { discutido a partir da Teoria da Fraca } \\
\text { Coerência Central, enquanto o } \\
\text { desempenho do grupo DL, a partir da } \\
\text { hipótese dos múltiplos déficits na } \\
\text { dislexia e considerando o impacto do } \\
\text { menor acesso a materiais escritos nas } \\
\text { habilidades visuoespaciais. }\end{array}$ \\
\hline $\begin{array}{l}\text { (6) Funcionamento } \\
\text { executivo, bem-estar } \\
\text { subjetivo, dupla } \\
\text { excepcionalidade }\end{array}$ & $\begin{array}{l}\text { Determinar um perfil de } \\
\text { desempenho executivo e } \\
\text { bem-estar subjetivo de } \\
\text { alunos que apresentam } \\
\text { Transtorno do Espectro } \\
\text { Autista e inteligência sobre } \\
\text { a faixa Média e determinar } \\
\text { diferenças } \\
\text { com um grupo de } \\
\text { estudantes com } \\
\text { desenvolvimento típico. }\end{array}$ & $\begin{array}{l}\text { Ao comparar funcionamento } \\
\text { executivo entre grupos, observou-se } \\
\text { que os alunos com DE apresentam } \\
\text { melhor desempenho em Raciocínio } \\
\text { Fluido ( } \mathrm{p}=0.04) \text { e, segundo a } \\
\text { percepção dos docentes, um melhor } \\
\text { controle Inibitório ( } \mathrm{p}=0,04) \text {. Apesar } \\
\text { de não terem sido encontradas outras } \\
\text { diferenças significativas entre grupos, o } \\
\text { perfil de alunos DE mostrou um } \\
\text { déficit em funções executivas, mas } \\
\text { apenas na manifestação } \\
\text { comportamental das mesmas. Os } \\
\text { resultados associados ao bem-estar } \\
\text { subjetivo, indicam que não existem } \\
\text { diferenças significativas entre grupos. } \\
\text { O perfil de alunos DE reflete que } \\
\text { mantêm "moderada" satisfação com a } \\
\text { vida e maior Afeto Positivo do que } \\
\text { Negativo }\end{array}$ \\
\hline $\begin{array}{l}\text { (7) Autismo; } \\
\text { Autoavaliação; Qualidade } \\
\text { de vida; Avaliação } \\
\text { qualitativa; Satisfação } \\
\text { pessoal; Síndrome de } \\
\text { Asperger; Transtorno do } \\
\text { espectro do autismo }\end{array}$ & $\begin{array}{l}\text { Explorar a percepção da } \\
\text { qualidade de vida de um } \\
\text { grupo de crianças e } \\
\text { adolescentes com TEA sem } \\
\text { deficiência intelectual } \\
\text { associada. }\end{array}$ & $\begin{array}{l}\text { Ambos os grupos relatam } \\
\text { positivamente a sua qualidade, sem } \\
\text { diferenças nas dimensões básicas. No } \\
\text { entanto, no caso dos adolescentes, } \\
\text { obtêm-se pontuações mais baixas na } \\
\text { área de autodeterminação em } \\
\text { comparação com as demais. }\end{array}$ \\
\hline $\begin{array}{l}\text { (8) Síndrome de } \\
\text { Asperger; Autismo de } \\
\text { alto funcionamento; } \\
\text { Avaliação } \\
\text { neuropsicológica; } \\
\text { Inteligência; } \\
\text { Desempenho executivo. }\end{array}$ & $\begin{array}{l}\text { O objetivo do estudo é } \\
\text { avaliar o perfil cognitivo de } \\
\text { funcionamento executivo } \\
\text { em crianças e adolescentes } \\
\text { com TEA-SDI e compará- } \\
\text { lo com o de controles } \\
\text { sadios pareados em sexo, }\end{array}$ & $\begin{array}{l}\text { Foram encontradas diferenças } \\
\text { estatisticamente significativas em todos } \\
\text { os domínios cognitivos avaliados a } \\
\text { favor de um melhor rendimento por } \\
\text { parte do grupo controle: atenção } \\
\text { (U=185, } 0 ; \mathrm{p}=0,0005 ; \mathrm{D}=0,90) \text {, } \\
\text { memória de trabalho (T51,48=2,597; }\end{array}$ \\
\hline
\end{tabular}




\begin{tabular}{|c|c|c|}
\hline & $\begin{array}{c}\text { idade, status } \\
\text { socioeconômico, nível } \\
\text { educacional e quociente } \\
\text { intelectual (CI). }\end{array}$ & $\begin{array}{c}\mathrm{p}=0,006 ; \mathrm{D}=0,72) \text {, flexibilidade } \\
\text { cognitiva }(\mathrm{U}=236,0 ; \mathrm{p}=0,007 ; \\
\mathrm{D}=0,67) \text {, controle inibitório }(\mathrm{U}=210,0 ; \\
\mathrm{p}=0,002 ; \mathrm{D}=0,71) \text { e solução de } \\
\text { problemas }(\mathrm{U}=261,0 ; \mathrm{p}=0,021 ; \\
\mathrm{D}=0,62) . \text { Estas diferenças } \\
\text { mantiveram-se quando as análises } \\
\text { foram realizadas através da verificação } \\
\text { de QI. }\end{array}$ \\
\hline $\begin{array}{l}\text { (9) Transtorno obsessivo } \\
\text { compulsivo (TOC), } \\
\text { Transtorno de Espectro } \\
\text { Autista (TEA), } \\
\text { sintomatologia obsessiva- } \\
\text { compulsiva. }\end{array}$ & $\begin{array}{l}\text { Descrever a prevalência de } \\
\text { comportamentos repetitivos } \\
\text { das crianças com TEA com } \\
\text { a adaptação espanhola do } \\
\text { Child Yale-Brown } \\
\text { Obsessive compulsive Scale } \\
\text { por Autism Spectrum } \\
\text { Disorder (CY-BOCSASD) e } \\
\text { comparar o tipo de } \\
\text { sintomas e gravidade com } \\
\text { aqueles avaliados em um } \\
\text { grupo de comparação com } \\
\text { TOC. }\end{array}$ & $\begin{array}{c}\text { Obtiveram-se pontuações mais altas } \\
\text { nos sintomas obsessivo-compulsivos } \\
\text { atuais no grupo de TOC }(12,95+3,45) \\
\text { que no grupo com TEA }(8.23+5.65) \text {, }(\mathrm{t} \\
=-3.632, \mathrm{p}=.001) \text {. As compulsões de } \\
\text { limpeza }(\mathrm{p}=.003) \text {, verificação }(\mathrm{p}=.001) \text {, } \\
\text { contagem ( } \mathrm{p}=.001) \text {, ordem e simetria } \\
(\mathrm{p}=.004) \text {, e miscelânea ( } \mathrm{p}=.001) \text { foram } \\
\text { significativamente mais prevalentes no } \\
\text { grupo de TOC. A frequência, } \\
\text { desconforto e interferência foi maior } \\
\text { em pacientes com TOC do que em } \\
\text { pacientes com TEA. }\end{array}$ \\
\hline
\end{tabular}

Fonte: As autoras, 2020

\section{RESULTADOS}

O cruzamento dos descritores revelou grande abrangência de artigos científicos, os quais foram selecionados por meio dos critérios de inclusão e exclusão. Quatrocentos e oito artigos foram recuperados resultando em nove eleitos.

Notou-se que alguns artigos se repetiram nas bases de dados e ou até mesmo na mesma base. Seis artigos são de língua espanhola, um de origem chilena, um panamenho, três espanhóis e três são brasileiros e redigidos em português.

Os artigos revisados são de finalidade básica, oito de natureza quantitativa e um quali-quanti, um apresenta objetivo exploratório e os demais, descritivo. Quanto aos procedimentos reconhecemos um estudo de caso, um experimental e sete levantamento de dados. O quadro 03 identifica o tipo de pesquisa do artigo eleito.

Quadro 03 - Identificação do tipo de pesquisa dos artigos da revisão integrativa

\begin{tabular}{|c|c|c|c|c|c|}
\hline $\begin{array}{c}\text { (1) Dançaterapia no } \\
\text { autismo: um estudo de } \\
\text { caso }\end{array}$ & Básica & Quantitativa & Descritiva & $\begin{array}{c}\text { Estudo de } \\
\text { caso }\end{array}$ & $\begin{array}{c}\text { A dança como } \\
\text { terapia para o } \\
\text { desenvolvimento } \\
\text { das funções } \\
\text { motoras em } \\
\text { autistas }\end{array}$ \\
\hline $\begin{array}{c}\text { (2) Procesamiento } \\
\text { semántico de palabras } \\
\text { epistémicas y } \\
\text { metafísicas en niños y } \\
\text { adolescentes con } \\
\text { Trastorno de Espectro }\end{array}$ & Básica & Quantitativa & Exploratória & Experimental & $\begin{array}{c}\text { Teoria da mente } \\
\text { e processamento } \\
\text { semânticos em } \\
\text { sujeitos autistas }\end{array}$ \\
\hline
\end{tabular}




\begin{tabular}{|c|c|c|c|c|c|}
\hline $\begin{array}{l}\text { Autista (TEA) y con } \\
\text { Desarrollo Típico } \\
\text { (DT). }\end{array}$ & & & & & \\
\hline $\begin{array}{c}\text { (3) Frequência de } \\
\text { sobrepeso e obesidade } \\
\text { em crianças e } \\
\text { adolescentes com } \\
\text { autismo e transtorno } \\
\text { do déficit de } \\
\text { atenção/hiperatividade }\end{array}$ & Básica & Quantitativa & Descritiva & $\begin{array}{c}\text { Levantamento } \\
\text { de dados }\end{array}$ & $\begin{array}{c}\text { Sobrepeso e } \\
\text { obesidade em } \\
\text { crianças e } \\
\text { adolescentes } \\
\text { autistas e TDAH }\end{array}$ \\
\hline $\begin{array}{l}\text { (4) Evolución y } \\
\text { seguimiento de } \\
\text { adolescentes y adultos } \\
\text { jóvenes con autismo }\end{array}$ & Básica & Quantitativa & Descritiva & $\begin{array}{c}\text { Levantamento } \\
\text { de dados }\end{array}$ & $\begin{array}{c}\text { Avaliação da } \\
\text { adaptação e } \\
\text { independência } \\
\text { na adolescência } \\
\text { e vida adulta de } \\
\text { sujeitos autistas }\end{array}$ \\
\hline $\begin{array}{l}\text { (5) Desempenho no } \\
\text { teste de raven: } \\
\text { diferenças entre } \\
\text { crianças-adolescentes } \\
\text { com transtorno do } \\
\text { espectro autista e com } \\
\text { dificuldades de leitura }\end{array}$ & Básica & Quantitativa & Descritiva & $\begin{array}{c}\text { Levantamento } \\
\text { de dados }\end{array}$ & $\begin{array}{l}\text { Comparação de } \\
\text { desempenho no } \\
\text { teste de Raven }\end{array}$ \\
\hline $\begin{array}{c}\text { (6) Funciones } \\
\text { ejecutivas y bienestar } \\
\text { subjetivo en alumnos } \\
\text { que presentan } \\
\text { trastorno del espectro } \\
\text { autista e inteligencia } \\
\text { sobre el rango } \\
\text { promedio }\end{array}$ & Básica & Quantitativa & Descritiva & $\begin{array}{c}\text { Levantamento } \\
\text { de dados }\end{array}$ & $\begin{array}{c}\text { Funções } \\
\text { executivas e bem } \\
\text { estar subjetivo } \\
\text { em alunos } \\
\text { autistas }\end{array}$ \\
\hline $\begin{array}{l}\text { (7) Calidad de vida en } \\
\text { niños y adolescentes } \\
\text { con trastorno del } \\
\text { espectro autista sin } \\
\text { discapacidad } \\
\text { intelectual } \\
\end{array}$ & Básica & Quantitativa & Descritiva & $\begin{array}{c}\text { Levantamento } \\
\text { de dados }\end{array}$ & $\begin{array}{c}\text { Qualidade de } \\
\text { vida de crianças } \\
\text { e adolescentes } \\
\text { autistas }\end{array}$ \\
\hline $\begin{array}{c}\text { (8) La función } \\
\text { ejecutiva está alterada } \\
\text { en los trastornos del } \\
\text { espectro autista, pero } \\
\text { esta no correlaciona } \\
\text { con la inteligencia }\end{array}$ & Básica & $\begin{array}{c}\text { Quali- } \\
\text { quantitativa }\end{array}$ & Descritiva & $\begin{array}{c}\text { Levantamento } \\
\text { de dados }\end{array}$ & $\begin{array}{c}\text { Funções } \\
\text { executivas em } \\
\text { sujeitos autistas }\end{array}$ \\
\hline $\begin{array}{c}\text { (9) Identificando } \\
\text { compulsiones en niños } \\
\text { y adolescentes con } \\
\text { trastorno del espectro } \\
\text { autista }\end{array}$ & Básica & Quantitativa & Descritiva & $\begin{array}{c}\text { Levantamento } \\
\text { de dados }\end{array}$ & $\begin{array}{l}\text { Compulsões em } \\
\text { crianças e } \\
\text { adolescentes } \\
\text { autistas }\end{array}$ \\
\hline
\end{tabular}

Fonte: As autoras, 2020

\section{DISCUSSÃO}


A discussão desta revisão integrativa será dividida em dois momentos: primeiro iremos debater, brevemente, os tipos de pesquisas que foram analisadas e, em seguida, iremos abordar os assuntos que foram discutidos nos artigos selecionados para esta revisão.

A pesquisa de finalidade básica, de acordo com Gil (2008), tem o objetivo de produzir novos conhecimentos à Ciência. Pesquisas de natureza quantitativa geram dados quantificáveis por meio da coleta sistemática de dados e apresentam forte influência positivista, recorre à linguagem matemática para descrever fenômenos, enquanto pesquisas quali-quantitativas exploram as interpretações das realidades sociais, subjetivas mesclando com as interpretações objetivas e matemáticas (LAKATOS, 2003; GIL, 2008; SOUZA., KERBAUY, 2017).

De acordo com Gil (2008), pesquisas exploratórias são realizadas com o intuito de aproximar o pesquisador ao tema, proporcionando uma visão geral acerca de determinado objeto de estudo. Este é um tipo de pesquisa empírica que, segundo Lakatos (2003, p. 188), tem "tripla finalidade: desenvolver hipóteses, aumentar a familiaridade do pesquisador com um ambiente, fato ou fenômeno, para a realização de uma pesquisa futura mais precisa ou modificar e clarificar conceitos." Lakatos (2003) afirma que, por meio dessas pesquisas, é possível obter-se descrições tanto qualitativas quanto quantitativas do fenômeno estudado. Enquanto as pesquisas descritivas tem como objetivo "a descrição das características de determinada população ou fenômeno ou o estabelecimento de relações entre variáveis [...] uma de suas características mais significativas está na utilização de técnicas padronizadas de coleta de dados." (GIL, 2008, p. 28). De acordo com Lakatos (2003, p. 187) se "aproximam dos projetos experimentais, caracterizados pela precisão e controle estatísticos, com a finalidade de fornecer dados para a verificação de hipóteses".

Gil (2008) e Carvalho et al. (2019) descrevem o estudo de caso como procedimento metodológico que tem como objetivo conhecer detalhadamente um caso específico. A pesquisa experimental "consiste em determinar um objeto de estudo, selecionar as variáveis que seriam capazes de influenciá-lo, definir as formas de controle e de observação dos efeitos que a variável produz no objeto." (GIL, 2008, p. 51). A pesquisa de levantamento "é o tipo de pesquisa que visa investigar algo que se pretende conhecer de uma determinada população. Nessa modalidade de pesquisa, define-se um problema e, a partir dele, criam-se meios de gerar informações (como um questionário, por exemplo) para - após a coleta e a análise dos dados - se chegar às conclusões.” (CARVALHO et al., p. 41).

Por meio da análise das características das pesquisas, observou-se que não houve grande abrangência de tipos de pesquisa, o que não se pode afirmar quanto aos assuntos, pois percebeu-se grande diversidade. Quanto à definição de TEA, notou-se correspondência entre as definições dos autores.

O Transtorno do espectro autista é descrito pelos autores Machado (2015), Flagge (2017), Cuesta-Gómez et al. (2016) e Ortiz et al. (2019) como um transtorno relacionado a socialização e comunicação que tem origem ainda na infância e pode se estender por toda vida. Machado (2015), enfatiza que as crianças que apresentam este transtorno apresentam dificuldades no desenvolvimento das habilidades de imitação e do uso espontâneo de gestos. Flagge (2017), afirma que o TEA é uma deficiência oculta por sua etiologia e evolução para a adolescência e vida adulta.

Cuesta-Gómez et al. (2016) descrevem como o DSM-5 categoriza este transtorno e explicam que o TEA é uma condição heterogênea e que a última edição do DSM apresenta o autismo enquadrado em uma seção mais ampla, sobre os distúrbios do neurodesenvolvimento, além de estabelecer critérios melhor definidos para o diagnóstico deste transtorno. Ortiz et al. (2019) explicita os critérios utilizados pelo DSM para o TEA, acentua como sintomas a dificuldade de comunicação social persistente e em contextos diversos, os padrões de comportamento restritos e/ou repetitivos e enfatiza que os sintomas devem aparecer desde os primeiros anos de vida do sujeito.

Machado (2015) e Flagge (2017) discutem que a origem da TEA ainda não está bem esclarecida. Machado (2015), levanta a hipótese de que este transtorno possa estar relacionado a problemas no sistema de neurônios espelho por considerar, segundo Ramachandran e Seckel apud Machado (2015), que este sistema fornece o mecanismo psicológico para a interação da percepção com a ação e é importante para o desenvolvimento de relações interpessoais e a aquisição motora por meio da imitação. Flagge (2017), afirma que o TEA possui uma base genética. 
A dificuldade de comunicação é uma das principais características do autismo. Juillerat et al. (2015) demonstram as limitações e potencialidades dos adolescentes com TEA na aquisição de repertório verbal relacionada a apropriação de palavras abstratas-metafísicas e abstratas-epistêmicas. A compreensão de palavras abstratas-epistêmicas, como imaginação, certeza, entre outras, é mais difícil e lenta que a compreensão de palavras abstratas-metafísicas, como liberdade, critério, entre outras. A relação entre as dificuldades de habilidades sociais e comunicação estão intimamente relacionadas à interpretação e compreensão destas palavras.

Quanto ao repertório não verbal, Sbicigo et al. (2019) sugerem que pessoas com TEA sejam avaliadas com testes de inteligência não verbal, por tarefas viso-espaciais que não demandam sobrecarga cognitiva, essas apresentam um potencial cognitivo não avaliado em outros tipos de testes, a não observância deste detalhe pode subestimar a capacidade do autista.

Sbicigo et al. (2019) afirmam que sujeitos autistas apresentam menor desempenho em testes que necessitam a resolução de problemas complexos que exigem maior flexibilidade cognitiva e memória de trabalho, o que explica as dificuldades nas funções executivas em TEA. Sobre isto, Merchán-Naranjo et al. (2016), ao aplicarem testes neuropsicológicos, a fim de relacionar as funções executivas à inteligência, percebem que crianças e adolescentes com TEA e sem deficiências intelectuais, apresentam, mesmo tendo o coeficiente de inteligência na média, dificuldades de atenção, em compreender e utilizar informações verbais mentalmente, latência nas respostas automáticas e na resolução de problemas.

Cuesta-Gómez et al. (2016), ao pesquisarem sobre a qualidade de vida de crianças e adolescentes com TEA sem deficiência intelectual, constatam que nos quesitos pesquisados (bem-estar físico, bem-estar emocional, bem-estar material, desenvolvimento pessoal, relações interpessoais, inclusão na comunidade e autodeterminação), os adolescentes apontaram satisfação em todos os tópicos pesquisados, apresentando variação na autodeterminação, o que se refere à tomada de decisões por si mesmos, demonstrando que esses adolescentes apresentam insatisfação nesta área. $O$ que não foi possível averiguar na pesquisa, é se essa insatisfação se refere à própria autonomia ou à relação familiar limitante.

Flagge (2017) demonstra que todos os adolescentes autistas, acompanhados desde os primeiros anos de vida, apresentam os sintomas do transtorno em algum grau ao longo da vida. De acordo com o autor, o desenvolvimento da linguagem e o grau de independência são os fatores de maior dificuldade em pessoas com TEA e isto influencia diretamente a capacidade de manter amizades. Quando estes fatores são pouco desenvolvidos podem gerar comportamentos de isolamento e sintomas depressivos, afirma.

As estereotipias, segundo Flagge (2017), são sintomas autísticos comuns, diminuem ao longo do desenvolvimento, mas persistem em 40\% dos autistas na vida adulta. Ortiz et al. (2019) comparam os comportamentos repetitivos dos adolescentes autistas com adolescentes diagnosticados com TOC (Transtorno obsessivo compulsivo) e constatam que a frequência, a intensidade do desconforto e a interferência produzida por compulsões em sujeito autistas é menor do que naqueles diagnosticados com TOC. Entre os fatores que explicam isto, Ortiz et al. (2019) acentuam que os autistas têm dificuldade em identificar emoções internas, dificuldades de processamento de informações complexas, no funcionamento cognitivo, o que limita a descrição dos seus estados e experiências mentais e experiências da vida diária. As autoras afirmam que o comportamento ritualístico desencadeia quadros ansiosos, depressivos e opositores desafiadores, enquanto os interesses restritos são negativos para quadros depressivos e os estereótipos preditivos de TDAH (transtorno de déficit de atenção e hiperatividade).

Kummer et al. (2016), ao pesquisar a frequência de sobrepeso e obesidade em crianças e adolescentes com TEA e TDAH, afirmam que eles são potencialmente mais vulneráveis a problemas relacionados ao ganho de peso que crianças e adolescentes com desenvolvimento típico. Utilizando a avaliação ponderal, explicam que fatores genéticos, hábitos alimentares e sedentarismo associados ao uso de fármacos como a risperidona aumentam as chances de autistas e TDAH apresentarem IMC (índice de massa corporal) mais alto que os demais. Frisam a importância do acompanhamento médico regular e da manutenção de hábitos saudáveis de vida.

Machado (2015) afirma que atividades que integram os diversos sistemas de atenção podem contribuir para a melhora da comunicação social e qualidade de vida dos sujeitos autistas. O programa 
de dançaterapia demonstrou sucesso no desenvolvimento das funções motoras, equilíbrio e marcha, passando as características de graves para moderadas nos parâmetros pesquisados em sujeito com TEA. O estudo representou um esboço de atividade para melhora da qualidade de vida de um adolescente autista, diminuindo a frequência dos movimentos estereotipados.

Para a abordagem integral das crianças e adolescentes autistas, de acordo com CuestaGómez et al. (2016) e Ortiz et al. (2019), há a necessidade de se desenvolver instrumentos e metodologias apropriadas para a avaliação e percepção subjetiva desses sujeitos, sobre a satisfação pessoal em TEA (CUESTA-GÓMEZ et al., 2016) e sobre identificação de sintomas compulsivos e (ORTIZ et al., 2019).

Flagge (2017) enfatiza a importância de programas que melhorem as habilidades sociais, de comunicação, de manejo de emoções e da resolução de problemas, a construção de grupos de apoio para pais e para pacientes com TEA. Agurto et al. (2019) consideram que práticas educativas são fundamentais para conhecer o funcionamento de estudantes autistas e responder aos desafios emocionais, familiares e educativos destes sujeitos. Cuesta-Gómez et al. (2016) afirmam que priorizar o desenvolvimento de habilidades de autoconsciência e autonomia desenvolve competências pessoais em pessoas com TEA. Machado (2015) conclui que intervenções que atuem em vários sistemas baseados em ritmo, dança contribuem para o desenvolvimento comportamental e motor desses sujeitos. Dessa forma, Kummer et al. (2016) afirmam que se torna de grande importância que clínicos experientes orientem seus pacientes com TEA e TDAH sobre hábitos saudáveis de vida.

\section{CONSIDERAÇÕES FINAIS}

Por meio deste estudo, foi possível caracterizar nove publicações científicas nacionais e internacionais de língua espanhola e portuguesa sobre transtorno do espectro autista (TEA) na adolescência, entre os anos de 2015 e 2020. Com a identificação das publicações, foi sintetizado e analisado os resultados, podendo conhecer como diferentes autores definem o autismo na adolescência e como apresentam como ponto comum a preocupação com os aspectos relacionados ao comportamento, às habilidades de comunicação e à autonomia.

Nota-se que há ênfase nos temas relacionados às dificuldades que os sujeitos autistas têm para manter relações sociais. Percebe-se que os pesquisadores e pesquisadoras tendem a trabalhar essas dificuldades e a enfatizar a necessidade de se criar meios para desenvolver habilidades e instrumentos de avaliação específicos para este público. Não é possível afirmar, por meio dos textos analisados, que a fase da adolescência interfere nos processos analisados.

Como limitação deste estudo, apontamos a busca de artigos em língua espanhola e portuguesa, impedindo ampliação de busca para um panorama mais diversificado da produção científica internacional. No entanto, podemos destacar que este estudo mostrou a importância de se investigar esse tema e ampliar as pesquisas tanto no âmbito nacional como internacional.

\section{REFERÊNCIAS}

AGURTO, Catalina Sabat; PÉREZ-SALAS, Claudia; VÉLIZ, Cristian Oyanedel. Funciones ejecutivas y bienestar subjetivo en alumnos que presentan trastorno del espectro autista e inteligencia sobre el rango promedio. Rev. chil. neuropsicol. v. 14, n. 2, p. 25-30, 2019. Disponível em: < https://pesquisa.bvsalud.org/portal/resource/pt/biblio-1102460>. Acesso em: 02 set. 2020.

\section{AMERICAN PSYCHIATRY ASSOCIATION. Diagnostic and Statistical Manual of Mental

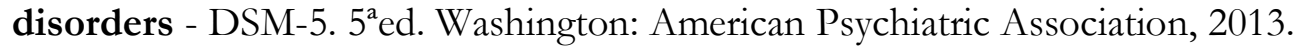

BAGAROLLO, Maria Fernanda; PANHOCA, Ivone. História de vida de adolescentes autistas: contribuições para a Fonoaudiologia e a Pediatria. Rev. paul. pediatr., São Paulo, v. 29, n. 1, p. 100-7, mar. 2011. Disponível em: <http://www.scielo.br/scielo.php?script=sci_arttext\&pid=S010305822011000100016\&lng=en\&nrm=iso > . Acesso em: 21 Ago. 2020. 
CAMARGO, Síglia Pimentel Höher; BOSA, Cleonice Alves. Competência social, inclusão escolar e autismo: revisão crítica da literatura. Psicol. Soc., Florianópolis, v. 21, n. 1, p. 65-74, abr. 2009.

Disponível em: <http://www.scielo.br/scielo.php?script=sci_arttext\&pid=S0102-

71822009000100008\&lng=en\&nrm=iso >. Acesso em: 19 abr. 2020

CAMARGO, Síglia Pimentel Höher et al . Desafios no processo de escolarização de crianças com autismo no contexto inclusivo: diretrizes para formação continuada na perspectiva dos

professores. Educ. rev., Belo Horizonte, v. 36, p.1-32, 2020. Disponível em

$<$ http:/ /www.scielo.br/scielo.php?script=sci_arttext\&pid=S0102-

46982020000100223\&lng=pt\&nrm=iso >. Acesso em: 01 nov. 2020.

CUESTA-GÓMEZ, José Luis; VIDRIALES-FERNÁNDEZ, Ruth; CARVAJAL-MOLINA,

Fernando. Calidad de vida en niños y adolescentes con trastorno del espectro autista sin discapacidad intelectual. Rev Neurol, Barcelona, v. 62, n.1, p. 33-39, 2016. Disponível em:

<https://www.neurologia.com/articulo/2015524> Acesso em: 02 set. 2020.

ERCOLE, Flavia Falci; MELO, Laís Samara; ALCOFORADO, Carla Lúcia Goulart Constan. Revisão Integrativa versus Revisão Sistemática. REME • Rev Min Enferm. Belo Horizonte, v.18, n. 1, p. 1214, 2014. Disponível em: < http://www.reme.org.br/artigo/detalhes/904>. Acesso em: 20 jun. 2020.

FLAGGE, Noris de Moreno. Evolución y seguimiento de adolescentes y adultos jóvenes con autismo. Pediátr. Panamá, v. 46, n. 2, p. 13-18, 2017. Disponível em: < https://pesquisa.bvsalud.org/portal/resource/pt/biblio-848211>. Acesso em: 02 Set. 2020.

GOMES, Paulyane. T. M. et al. Autismo no Brasil, desafios familiares e estratégias de superação: revisão sistemática. J. Pediatr. (Rio J.), Porto Alegre, v. 91, p. 111-21, abr. 2015. Disponível em: $<$ http:/ /www.scielo.br/scielo.php?script=sci_arttext\&pid=S002175572015000200111\&lng=en\&nrm=iso >. Acesso em: 19 abr. 2020.

HERVAS, Amaia. Un autismo, varios autismos. Variabilidad fenotípica en los trastornos del espectro autista. Rev Neurol., Barcelona, v. 62, n.1, p. 9-14, 2016. Disponível em: <https://www.neurologia.com/articulo/2016068>. Acesso em: 02 set. 2020.

HULL, Laura; PETRIDES, K. V; MANDY, Willian. The Female Autism Phenotype and Camouflaging: a Narrative Review. Rev J Autism Dev Disord, London, v. 7, p. 306-317, 2020. Disponível em: <https://link.springer.com/article/10.1007/s40489-020-00197-9>. Acesso em: 18 abr. 2021.

KLIN, Ami. Autismo e síndrome de Asperger: uma visão geral. Rev. Bras. Psiquiatr., São Paulo, v.28, p. 3-11, 2006. Disponível em: <http://www.scielo.br/scielo.php?script=sci_arttext\&pid=S151644462006000500002\&lng=en\&nrm=iso >. Acesso em: 30 mar. 2020.

KLIN, Ami; MERCADANTE, Marcos T. Autismo e transtornos invasivos do desenvolvimento. Rev. Bras. Psiquiatr., São Paulo, v.28, p. 1-2, 2006. Disponível em:

$<$ http:/ / www.scielo.br/scielo.php?script=sci_arttext\&pid=S151644462006000500001\&lng=en\&nrm=iso >. Acesso em: 30 mar. 2020.

JUILLERAT, Karen L. et alProcesamiento semántico de palabras epistémicas y metafísicas en niños y adolescentes con Trastorno de Espectro Autista (TEA) y con Desarrollo Típico (DT). Ter Psicol [online], Santiago , v. 33, n. 3, p. 221-238, 2015. Disponível em: $<$ https://scielo.conicyt.cl/scielo.php?script=sci_abstract\&pid=S071848082015000300006\&lng=pt\&nrm=iso > Acesso em: 30 mar. 2020. 
KUMMER, Arthur et al. Frequência de sobrepeso e obesidade em crianças e adolescentes com autismo e transtorno do déficit de atenção/hiperatividade. Rev. paul. pediatr., São Paulo, v. 34, n. 1, 2016. Disponível em: <http://www.scielo.br/scielo.php?script=sci_arttext\&pid=S010305822016000100071\&lng=en\&nrm=iso>. Acesso em: 02 Set. 2020.

MACHADO, Lavinia Teixeira. Dançaterapia no autismo: um estudo de caso. Fisioter. Pesqui. São Paulo, v. 22, n. 2, p. 205-211, 2015. Disponível em:

$<$ http://www.scielo.br/scielo.php?script=sci_arttext\&pid=S1809-

29502015000200205\&lng=en\&nrm=iso >. Acesso em: 02 de set. 2020.

MAENNER, Mattew J; SHAW, Kelly A.; BAIO, Jon et al. Prevalence of Autism Spectrum Disorder Among Children Aged 8 Years - Autism and Developmental Disabilities Monitoring Network, 11 Sites, United States, 2016. MMWR Surveill Summ. V. 69, n. 4, p. 1-12, 2020. Disponível em:

<https://www.ncbi.nlm.nih.gov/pmc/articles/PMC7119644/>. Acesso em: 29 mar. 2020.

MERCHÁN-NARANJO, Jessica et al. La función ejecutiva está alterada en los trastornos del espectro autista, pero esta no correlaciona con la inteligência. Revista de Psiquiatría y Salud Mental, v. 9, n. 1, p. 39-50, 2016. Disponível em: <

https://www.sciencedirect.com/science/article/abs/pii/S1888989115001883?via\%3Dihub>. Acesso em: 02 set. 2020.

MINATEL, Martha Morais; MATSUKURA, Thelma Simões. Familiares de crianças e adolescentes com autismo: percepções do contexto escolar. Revista Educação Especial, Santa Maria, v. 28, n. 52, p. 429-442, 2015. Disponível em:

<https://periodicos.ufsm.br/educacaoespecial/article/view/14708/pdf>. Acesso em: 20 out. 2020.

MINAYO, Maria Cecília de Souza. Análise qualitativa: teoria, passos e fidedignidade. Ciênc. saúde coletiva, Rio de Janeiro, v. 17, n.3, 2012 . Disponível

em<http://www.scielo.br/scielo.php?script=sci_

arttext\&pid=S1413-81232012000300007\&lng=en\&nrm=iso >. Acesso em: 22 jun. 2020.

ORTIZ, A. E. et al. Identificando compulsiones en niños y adolescentes con trastorno del espectro autista. Rev. psiquiatr. infanto-juv, vol. 36, núm. 4, p. 24-40, 2019. Disponível em: < https://pesquisa.bvsalud.org/portal/resource/pt/ibc-187870>. Acesso em: 02 set. 2020.

PAULON, Simone Mainieri et al. Documento subsidiário à política de inclusão Ministério da Educação. Secretaria de Educação Especial, Brasília: 2005.

ROMAN, Arlete Regina; FRIEDLANDER, Maria Romana. Revisão integrativa de pesquisa aplicada à enfermagem. Cogitare Enfermagem, Curitiba, vol. 3, núm. 2, p.109-112, 1998. Disponível em: <https://revistas.ufpr.br/cogitare/article/view/44358> Acesso em: 20 jun. 2020.

SBICIGO, Juliana Burges. et al. Desempenho no teste de Raven: diferenças entre crianças-adolescentes com transtorno do espectro autista e com dificuldades de leitura. Aval. psicol., Itatiba , v. 18, n. 2, p. 192-200, 2019. Disponível em: <http://pepsic.bvsalud.org/scielo.php?script=sci_arttext\&pid=S167704712019000200011\&lng=pt\&nrm=iso > . Acesso em: 02 set. 2020.

SEVILLA, María del Sol Fortae; BERMÚDEZ, María Olga Escandell; SÁNCHES, José Juan Castro. Aumento de la prevalencia de los transtornos del espectro autista: una revisión teórica. International Journal of Developmental and Educational Psychology, v. 01, n. 1, p.746-776, 2013. Disponível em: <https://www.redalyc.org/articulo.oa?id=349852058061>. Acesso: 29 mar. 2020. 
SOUZA, Marcela Tavares; SILVA, Michelly Dias; CARVALHO, Rachel. Revisão integrativa: o que é e como fazer. Einstein, p. 102-106, 2010. Disponível em:

<https://www.scielo.br/pdf/eins/v8n1/pt_1679-4508-eins-8-1-0102.pdf>. Acesso em: 15 set. 2019.

TCHUMAN, Roberto F.; RAPIN, Isabelle. Autismo abordagem neurobiológica. Porto Alegre Editora Artmed, 2009.

TEODORO, Graziele, C; GODINHO, Maíra, C. S.; HACHIMINE, Aparecida H. F. A inclusão de alunos com Transtorno do Espectro Autista no Ensino Fundamental. Research, Society and Development, v. 1, n. 2, p. 127-143, 2016. Disponível em:

file://C:/Users/Fabiana/Downloads/DialnetAInclusaoDeAlunosComTranstornoDoEspectroAutista NoE-6070066.pdf. Acesso em: 15 set. de 2019.

Submetido: $27 / 11 / 2020$

Aprovado: 07/06/2021 